\title{
Coupled coincidence points for compatible mappings satisfying mixed monotone property
}

\author{
Hemant Kumar Nashine ${ }^{a}$, Bessem Samet ${ }^{b}$, Calogero Vetro ${ }^{c, *}$ \\ ${ }^{a}$ Department of Mathematics, Disha Institute of Management and Technology, Satya Vihar, Vidhansabha-Chandrakhuri Marg, \\ Naradha, Mandir Hasaud, Raipur-492101(Chhattisgarh), India \\ ${ }^{b}$ Ecole Supérieure des Sciences et Techniques de Tunis, Département de Mathématiques, 5, avenue Taha Hussein-Tunis, B.P.:56, \\ Bab Menara-1008, Tunisie \\ ${ }^{c}$ Dipartimento di Matematica e Informatica, Università degli Studi di Palermo, via Archirafi 34, 90123 Palermo, Italy \\ This paper is dedicated to Professor Ljubomir Ćirić \\ Communicated by Professor V. Berinde
}

\begin{abstract}
We establish coupled coincidence and coupled fixed point results for a pair of mappings satisfying a compatibility hypothesis in partially ordered metric spaces. An example is given to illustrate our obtained results.(C)2012 NGA. All rights reserved.
\end{abstract}

Keywords: Compatible mappings, Coupled fixed point, mixed monotone property, partially ordered set 2010 MSC: 54H25, 47H10

\section{Introduction and Preliminaries}

In the last years, fixed points of mappings in partially ordered metric spaces have been investigated by many researchers $[1,2,3,6,7,8,9,10,12,13,14,15,16,18,19,20,21,22$. The first result in this direction was given by Ran and Reurings [17, Theorem 2.1] who presented its applications to linear and nonlinear metric spaces. Subsequently, Nieto and Rodŕiguez-López [15] extended the result of Ran and Reurings [17] for non-decreasing mappings and applied it to obtain a unique solution for a first order ordinary differential equation with periodic boundary conditions. Similar applications based on a version of Theorems 2.1-2.5 [15] for a mixed monotone mapping $F: X \times X \rightarrow X$ were given by Bhaskar and Lakshmikantham [4]. In

\footnotetext{
${ }^{*}$ Corresponding author

Email addresses: drhknashine@gmail.com (Hemant Kumar Nashine), bessem.samet@gmail.com (Bessem Samet), cvetro@math.unipa.it (Calogero Vetro)
} 
[4], Bhaskar and Lakshmikantham introduced the notion of a coupled fixed point and proved some coupled fixed point theorems for mappings satisfying a mixed monotone property. They discussed the problem of uniqueness of coupled fixed point and applied their theorems to problems of existence and uniqueness of solution for a periodic boundary value problem. Recently, Lakshmikantham and Ćirić [11] introduced the concept of mixed $g$-monotone mapping and proved coupled coincidence and coupled common fixed point theorems for commuting mappings, extending the theorems due to Bhaskar and Lakshmikantham [4]. Successively, Choudhury and Kundu [5], introduced the notion of compatibility of mappings in a partially ordered metric space and used this notion to establish a coupled coincidence point result which extends the works of Bhaskar and Lakshmikantham [4] and Lakshmikantham and Ćirić [11].

Now, we recall some definitions introduced in [4, 5, 11].

Let $(X, \preceq)$ be a partially ordered set and $F: X \rightarrow X$ be a mapping. The mapping $F$ is said to be non-decreasing if for all $x, y \in X, x \preceq y$ implies $F(x) \preceq F(y)$. Similarly, $F$ is said to be non-increasing, if for all $x, y \in X, x \preceq y$ implies $F(x) \succeq F(y)$.

Bhaskar and Lakshmikantham [4] introduced the following notions of mixed monotone mapping and coupled fixed point.

Definition 1.1. Let $(X, \preceq)$ be a partially ordered set and $F: X \times X \rightarrow X$. The mapping $F$ is said to have the mixed monotone property if $F$ is monotone non-decreasing in its first argument and is monotone non-increasing in its second argument, that is, for all $x_{1}, x_{2} \in X, x_{1} \preceq x_{2}$ implies $F\left(x_{1}, y\right) \preceq F\left(x_{2}, y\right)$, for any $y \in X$ and for all $y_{1}, y_{2} \in X, y_{1} \preceq y_{2}$ implies $F\left(x, y_{1}\right) \succeq F\left(x, y_{2}\right)$, for any $x \in X$.

The concept of the mixed monotone property is generalized by Lakshmikantham and Ćirić [1] as follows.

Definition 1.2. [1]. Let $(X, \preceq)$ be a partially ordered set and $F: X \times X \rightarrow X$ and $g: X \rightarrow X$. The mapping $F$ is said to have the mixed $g$-monotone property if $F$ is monotone $g$-non-decreasing in its first argument and is monotone $g$-non-increasing in its second argument, that is, for all $x_{1}, x_{2} \in X, g\left(x_{1}\right) \preceq g\left(x_{2}\right)$ implies $F\left(x_{1}, y\right) \preceq F\left(x_{2}, y\right)$, for any $y \in X$ and for all $y_{1}, y_{2} \in X, g\left(y_{1}\right) \preceq g\left(y_{2}\right)$ implies $F\left(x, y_{1}\right) \succeq F\left(x, y_{2}\right)$, for any $x \in X$.

Clearly, if $g$ is the identity mapping, then Definition 1.2 reduces to Definition 1.1 .

Definition 1.3. An element $(x, y) \in X \times X$ is called a coupled fixed point of the mapping $F: X \times X \rightarrow X$ if $F(x, y)=x$ and $F(y, x)=y$.

Definition 1.4. An element $(x, y) \in X \times X$ is called a coupled coincidence point of the mappings $F$ : $X \times X \rightarrow X$ and $g: X \rightarrow X$ if $F(x, y)=g(x)$ and $F(y, x)=g(y)$.

Definition 1.5. Let $(X, d)$ be a metric space, $F: X \times X \rightarrow X$ and $g: X \rightarrow X$. Then, $F$ and $g$ are compatible if

$$
\lim _{n \rightarrow+\infty} d\left(g\left(F\left(x_{n}, y_{n}\right)\right), F\left(g\left(x_{n}\right), g\left(y_{n}\right)\right)\right)=0
$$

and

$$
\lim _{n \rightarrow+\infty} d\left(g\left(F\left(y_{n}, x_{n}\right)\right), F\left(g\left(y_{n}\right), g\left(x_{n}\right)\right)\right)=0
$$

whenever $\left\{x_{n}\right\}$ and $\left\{y_{n}\right\}$ are sequences in $X$, such that

$$
\lim _{n \rightarrow+\infty} F\left(x_{n}, y_{n}\right)=\lim _{n \rightarrow+\infty} g\left(x_{n}\right)=x \text { and } \lim _{n \rightarrow+\infty} F\left(y_{n}, x_{n}\right)=\lim _{n \rightarrow+\infty} g\left(y_{n}\right)=y
$$

for all $x, y \in X$.

In this paper, we generalize the results of Bhaskar and Lakshmikantham [4] by considering generalized contractive conditions for a pair of mappings and prove results concerning coupled coincidence point and coupled fixed point. We give also an example to illustrate our results. 


\section{The Main Result}

Our first result is the following coupled coincidence point theorem.

Theorem 2.1. Let $(X, \preceq)$ be a partially ordered set and suppose there is a metric $d$ on $X$ such that $(X, d)$ is a complete metric space. Let $F: X \times X \rightarrow X$ and $g: X \rightarrow X$ be mappings such that $F$ has the mixed $g$-monotone property on $X$ and there exist two elements $x_{0}, y_{0} \in X$ with $g\left(x_{0}\right) \preceq F\left(x_{0}, y_{0}\right)$ and $g\left(y_{0}\right) \succeq F\left(y_{0}, x_{0}\right)$. Suppose there exist non-negative real numbers $\alpha, \beta, L$ with $\alpha+\beta<1$ such that

$$
\begin{aligned}
d(F(x, y), F(u, v)) \leq & \alpha \min \{d(F(x, y), g(x)), d(F(u, v), g(x))\}+\beta \min \{d(F(x, y), g(u)), d(F(u, v), g(u))\} \\
& +L \min \{d(F(x, y), g(u)), d(F(u, v), g(x))\}
\end{aligned}
$$

for all $(x, y),(u, v) \in X \times X$ with $g(x) \preceq g(u)$ and $g(y) \succeq g(v)$. Further suppose that $F(X \times X) \subseteq g(X), g$ is continuous non-decreasing, $g$ and $F$ are compatible and also either

(a) F is continuous or

(b) $X$ has the following property:

(i) if a non-decreasing sequence $\left\{x_{n}\right\}$ in $X$ converges to $x \in X$, then $x_{n} \preceq x$ for all $n$,

(ii) if a non-increasing sequence $\left\{y_{n}\right\}$ in $X$ converges to $y \in X$, then $y_{n} \succeq y$ for all $n$,

holds. Then, there exist $x, y \in X$ such that $F(x, y)=g(x)$ and $F(y, x)=g(y)$, that is, $F$ and $g$ have a coupled coincidence point $(x, y) \in X \times X$.

Proof. Let $x_{0}, y_{0} \in X$ be such that $g\left(x_{0}\right) \preceq F\left(x_{0}, y_{0}\right)$ and $g\left(y_{0}\right) \succeq F\left(y_{0}, x_{0}\right)$. Since $F(X \times X) \subseteq g(X)$, we can choose $x_{1}, y_{1} \in X$ such that $g\left(x_{1}\right)=F\left(x_{0}, y_{0}\right)$ and $g\left(y_{1}\right)=F\left(y_{0}, x_{0}\right)$.

Analogously, there exist $x_{2}, y_{2} \in X$ such that $g\left(x_{2}\right)=F\left(x_{1}, y_{1}\right)$ and $g\left(y_{2}\right)=F\left(y_{1}, x_{1}\right)$.

Continuing this process, we can construct two sequences $\left\{x_{n}\right\}$ and $\left\{y_{n}\right\}$ in $X$ such that

$$
g\left(x_{n+1}\right)=F\left(x_{n}, y_{n}\right) \text { and } g\left(y_{n+1}\right)=F\left(y_{n}, x_{n}\right) \forall n \geq 0 .
$$

Now we prove that for all $n \geq 0$,

$$
g\left(x_{n}\right) \preceq g\left(x_{n+1}\right) \text { and } g\left(y_{n}\right) \succeq g\left(y_{n+1}\right) .
$$

We shall use the mathematical induction. Let $n=0$, since $g\left(x_{0}\right) \preceq F\left(x_{0}, y_{0}\right)$ and $g\left(y_{0}\right) \succeq F\left(y_{0}, x_{0}\right)$, in view of $g\left(x_{1}\right)=F\left(x_{0}, y_{0}\right)$ and $g\left(y_{1}\right)=F\left(y_{0}, x_{0}\right)$, we have $g\left(x_{0}\right) \preceq g\left(x_{1}\right)$ and $g\left(y_{0}\right) \succeq g\left(y_{1}\right)$, that is, (2.3) holds for $n=0$. We assume that (2.3) hold for some $n>0$. As $F$ has the mixed $g$-monotone property and $g\left(x_{n}\right) \preceq g\left(x_{n+1}\right), g\left(y_{n}\right) \succeq g\left(y_{n+1}\right)$, from $(2.2)$, we get

$$
g\left(x_{n+1}\right)=F\left(x_{n}, y_{n}\right) \preceq F\left(x_{n+1}, y_{n}\right), \quad F\left(y_{n+1}, x_{n}\right) \preceq F\left(y_{n}, x_{n}\right)=g\left(y_{n+1}\right) .
$$

Also for the same reason we have

$$
g\left(x_{n+2}\right)=F\left(x_{n+1}, y_{n+1}\right) \succeq F\left(x_{n+1}, y_{n}\right), F\left(y_{n+1}, x_{n}\right) \succeq F\left(y_{n+1}, x_{n+1}\right)=g\left(y_{n+2}\right) .
$$

Merging the above results, we obtain $g\left(x_{n+1}\right) \preceq g\left(x_{n+2}\right)$ and $g\left(y_{n+1}\right) \succeq g\left(y_{n+2}\right)$.

Thus by the mathematical induction, we conclude that $(2.3)$ holds for all $n \geq 0$.

We check easily that

$$
g\left(x_{0}\right) \preceq g\left(x_{1}\right) \preceq g\left(x_{2}\right) \preceq \cdots \preceq g\left(x_{n+1}\right) \preceq \cdots
$$

and

$$
g\left(y_{0}\right) \succeq g\left(y_{1}\right) \succeq g\left(y_{2}\right) \succeq \cdots \succeq g\left(y_{n+1}\right) \succeq \cdots .
$$


Since $g\left(x_{n}\right) \succeq g\left(x_{n-1}\right)$ and $g\left(y_{n}\right) \preceq g\left(y_{n-1}\right)$, from (2.1) and (2.2), we have

$$
\begin{aligned}
d\left(g\left(x_{n+1}\right), g\left(x_{n}\right)\right)= & d\left(F\left(x_{n}, y_{n}\right), F\left(x_{n-1}, y_{n-1}\right)\right. \\
\leq & \alpha \min \left\{d\left(F\left(x_{n}, y_{n}\right), g\left(x_{n}\right)\right), d\left(F\left(x_{n-1}, y_{n-1}\right), g\left(x_{n}\right)\right)\right\} \\
& +\beta \min \left\{d\left(F\left(x_{n}, y_{n}\right), g\left(x_{n-1}\right)\right), d\left(F\left(x_{n-1}, y_{n-1}\right), g\left(x_{n-1}\right)\right)\right\} \\
& +L \min \left\{d\left(F\left(x_{n}, y_{n}\right), g\left(x_{n-1}\right)\right), d\left(F\left(x_{n-1}, y_{n-1}\right), g\left(x_{n}\right)\right)\right\},
\end{aligned}
$$

that is

$$
d\left(g\left(x_{n+1}\right), g\left(x_{n}\right)\right) \leq \beta d\left(g\left(x_{n}\right), g\left(x_{n-1}\right)\right) .
$$

Similarly, since $g\left(y_{n-1}\right) \succeq g\left(y_{n}\right)$ and $g\left(x_{n-1}\right) \preceq g\left(x_{n}\right)$, from (2.1) and (2.2), we have

$$
d\left(g\left(y_{n}\right), g\left(y_{n+1}\right)\right) \leq \alpha d\left(g\left(y_{n}\right), g\left(y_{n-1}\right)\right) .
$$

From (2.5) and (2.6), we have

$$
\begin{aligned}
d\left(g\left(x_{n+1}\right), g\left(x_{n}\right)\right)+d\left(g\left(y_{n}\right), g\left(y_{n+1}\right)\right) & \leq \beta d\left(g\left(x_{n}\right), g\left(x_{n-1}\right)\right)+\alpha d\left(g\left(y_{n}\right), g\left(y_{n-1}\right)\right) \\
& \leq(\alpha+\beta) d\left(g\left(x_{n}\right), g\left(x_{n-1}\right)\right)+(\alpha+\beta) d\left(g\left(y_{n}\right), g\left(y_{n-1}\right)\right) \\
& =(\alpha+\beta)\left[d\left(g\left(x_{n}\right), g\left(x_{n-1}\right)\right)+d\left(g\left(y_{n}\right), g\left(y_{n-1}\right)\right)\right] .
\end{aligned}
$$

Set $\rho_{n}=d\left(g\left(x_{n+1}\right), g\left(x_{n}\right)\right)+d\left(g\left(y_{n+1}\right), g\left(y_{n}\right)\right)$ and $\delta=\alpha+\beta$, then the sequence $\left\{\rho_{n}\right\}$ is decreasing as

$$
0 \leq \rho_{n} \leq \delta \rho_{n-1} \leq \delta^{2} \rho_{n-2} \leq \cdots \leq \delta^{n} \rho_{0}
$$

which implies

$$
\lim _{n \rightarrow+\infty} \rho_{n}=\lim _{n \rightarrow+\infty}\left[d\left(g\left(x_{n+1}\right), g\left(x_{n}\right)\right)+d\left(g\left(y_{n+1}\right), g\left(y_{n}\right)\right)\right]=0 .
$$

Thus,

$$
\left.\lim _{n \rightarrow+\infty} d\left(g\left(x_{n+1}\right), g\left(x_{n}\right)\right)=0 \text { and } \lim _{n \rightarrow+\infty} d\left(g\left(y_{n+1}\right), g\left(y_{n}\right)\right)\right]=0 .
$$

In what follows, we shall prove that $\left\{g\left(x_{n}\right)\right\}$ and $\left\{g\left(y_{n}\right)\right\}$ are Cauchy sequences.

For each $m \geq n$, we have

$$
d\left(g\left(x_{m}\right), g\left(x_{n}\right)\right) \leq d\left(g\left(x_{m}\right), g\left(x_{m-1}\right)\right)+d\left(g\left(x_{m-1}\right), g\left(x_{m-2}\right)\right)+\cdots+d\left(g\left(x_{n+1}\right), g\left(x_{n}\right)\right)
$$

and

$$
d\left(g\left(y_{m}\right), g\left(y_{n}\right)\right) \leq d\left(g\left(y_{m}\right), g\left(y_{m-1}\right)\right)+d\left(g\left(y_{m-1}\right), g\left(y_{m-2}\right)\right)+\cdots+d\left(g\left(y_{n+1}\right), g\left(y_{n}\right)\right) .
$$

Therefore

$$
\begin{aligned}
d\left(g\left(x_{m}\right), g\left(x_{n}\right)\right)+d\left(g\left(y_{m}\right), g\left(y_{n}\right)\right) & \leq \rho_{m-1}+\rho_{m-2}+\cdots+\rho_{n} \\
& \leq\left(\delta^{m-1}+\delta^{m-2}+\cdots+\delta^{n}\right) \rho_{0} \\
& \leq \frac{\delta^{n}}{1-\delta} \rho_{0}
\end{aligned}
$$

which implies that

$$
\lim _{n, m \rightarrow+\infty}\left[d\left(g\left(x_{m}\right), g\left(x_{n}\right)\right)+d\left(g\left(y_{m}\right), g\left(y_{n}\right)\right)\right]=0 .
$$

This imply that $\left\{g\left(x_{n}\right)\right\}$ and $\left\{g\left(y_{n}\right)\right\}$ are Cauchy sequences in $X$. Now, since $(X, d)$ is a complete metric space, there exists $(x, y) \in X \times X$ such that

$$
\lim _{n \rightarrow+\infty} F\left(x_{n}, y_{n}\right)=\lim _{n \rightarrow+\infty} g\left(x_{n}\right)=x \quad \text { and } \quad \lim _{n \rightarrow+\infty} F\left(y_{n}, x_{n}\right)=\lim _{n \rightarrow+\infty} g\left(y_{n}\right)=y .
$$


From (2.8) and the continuity of $g$, we get

$$
\lim _{n \rightarrow+\infty} g\left(g\left(x_{n}\right)\right)=g(x) \text { and } \lim _{n \rightarrow+\infty} g\left(g\left(y_{n}\right)\right)=g(y) .
$$

From 2.2 and the compatibility of $F$ and $g$, we have

$$
\left\{\begin{array}{l}
\lim _{n \rightarrow+\infty} d\left(g\left(F\left(x_{n}, y_{n}\right)\right), F\left(g\left(x_{n}\right), g\left(y_{n}\right)\right)\right)=0 \\
\lim _{n \rightarrow+\infty} d\left(g\left(F\left(y_{n}, x_{n}\right)\right), F\left(g\left(y_{n}\right), g\left(x_{n}\right)\right)\right)=0
\end{array}\right.
$$

Finally, we claim that $(x, y)$ is a coupled coincidence point of $F$ and $g$.

Taking the limit as $n \rightarrow+\infty$ in (2.10), by (2.2), 2.8), 2.9) and the continuity of $F$, we get

$$
\begin{aligned}
g(x)=\lim _{n \rightarrow+\infty} g\left(g\left(x_{n+1}\right)\right) & =\lim _{n \rightarrow+\infty} F\left(g\left(x_{n}\right), g\left(y_{n}\right)\right) \\
& =F\left(\lim _{n \rightarrow+\infty} g\left(x_{n}\right), \lim _{n \rightarrow+\infty} g\left(y_{n}\right)\right)=F(x, y), \\
g(y)=\lim _{n \rightarrow+\infty} g\left(g\left(y_{n+1}\right)\right) & =\lim _{n \rightarrow+\infty} F\left(g\left(y_{n}\right), g\left(x_{n}\right)\right) \\
& =F\left(\lim _{n \rightarrow+\infty} g\left(y_{n}\right), \lim _{n \rightarrow+\infty} g\left(x_{n}\right)\right)=F(y, x) .
\end{aligned}
$$

Thus, we proved that $F(x, y)=g(x)$ and $F(y, x)=g(y)$.

Now, suppose that $(b)$ holds. Since $\left\{g\left(x_{n}\right)\right\}$ is non-decreasing and $g\left(x_{n}\right) \rightarrow x$, and $\left\{g\left(y_{n}\right)\right\}$ is non-increasing and $g\left(y_{n}\right) \rightarrow y$, by assumption $(b)$, we have $g\left(g x_{n}\right) \preceq g(x)$ and $g\left(g y_{n}\right) \succeq g(y)$ for all $n$. Then, we get

$$
\begin{aligned}
d(g(x), F(x, y)) \leq & d\left(g(x), g\left(g\left(x_{n+1}\right)\right)\right)+d\left(g\left(g\left(x_{n+1}\right)\right), F(x, y)\right) \\
= & d\left(g(x), g\left(g\left(x_{n+1}\right)\right)\right)+d\left(g\left(F\left(x_{n}, y_{n}\right)\right), F(x, y)\right) \\
= & d\left(g(x), g\left(g\left(x_{n+1}\right)\right)\right)+d\left(g\left(F\left(x_{n}, y_{n}\right)\right), F\left(g\left(x_{n}\right), g\left(y_{n}\right)\right)\right) \\
& +d\left(F\left(g\left(x_{n}\right), g\left(y_{n}\right)\right), F(x, y)\right) \\
\leq & d\left(g(x), g\left(g\left(x_{n+1}\right)\right)\right)+d\left(g\left(F\left(x_{n}, y_{n}\right)\right), F\left(g\left(x_{n}\right), g\left(y_{n}\right)\right)\right) \\
& +\alpha \min \left\{d\left(F\left(g\left(x_{n}\right), g\left(y_{n}\right)\right), g\left(g x_{n}\right)\right), d\left(F(x, y), g\left(g\left(x_{n}\right)\right)\right)\right\} \\
& +\beta \min \left\{d\left(F\left(g\left(x_{n}\right), g\left(y_{n}\right)\right), g(x)\right), d(F(x, y), g(x))\right\}+ \\
& \left.+L \min \left\{F\left(g\left(x_{n}\right), g\left(y_{n}\right)\right), g(x)\right), d\left(F(x, y), g\left(g\left(x_{n}\right)\right)\right)\right\} .
\end{aligned}
$$

Taking the limit as $n \rightarrow+\infty$ in the above inequality and using (2.8) and (2.10), we get $d(g(x), F(x, y))=0$. Hence $g(x)=F(x, y)$. Similarly, one can show that $g(y)=F(y, x)$. Thus $F$ and $g$ have a coupled coincidence point. This makes end to the proof.

If $g=I$, the identity mapping in Theorem 2.1, then we deduce the following result of coupled fixed point.

Corollary 2.2. Let $(X, \preceq)$ be a partially ordered set and suppose there is a metric $d$ on $X$ such that $(X, d)$ is a complete metric space. Let $F: X \times X \rightarrow X$ be a mapping such that $F$ has the mixed monotone property on $X$ and there exist two elements $x_{0}, y_{0} \in X$ with $x_{0} \preceq F\left(x_{0}, y_{0}\right)$ and $y_{0} \succeq F\left(y_{0}, x_{0}\right)$. Also suppose there exist non-negative real numbers $\alpha, \beta$ and $L$ with $\alpha+\beta<1$ such that

$$
\begin{aligned}
d(F(x, y), F(u, v)) \leq & \alpha \min \{d(F(x, y), x), d(F(u, v), x)\}+\beta \min \{d(F(x, y), u), d(F(u, v), u)\} \\
& +L \min \{d(F(x, y), u), d(F(u, v), x)\},
\end{aligned}
$$

for all $(x, y),(u, v) \in X \times X$ with $x \succeq u$ and $y \preceq v$ and either $(a)$ or $(b)$ of Theorem 2.1 holds. Then, there exist $x, y \in X$ such that $F(x, y)=x$ and $F(y, x)=y$, that is, $F$ has a coupled fixed point $(x, y) \in X \times X$.

Remark 2.3. By choosing $\alpha, \beta$ and $L$ suitably, one can deduce some corollaries from Theorem 2.1 .

For example, if $\alpha=\beta=0$ in Theorem 2.1, then we can state the following corollary. 
Corollary 2.4. Let $(X, \preceq)$ be a partially ordered set and suppose there is a metric $d$ on $X$ such that $(X, d)$ is a complete metric space. Let $F: X \times X \rightarrow X$ and $g: X \rightarrow X$ be mappings such that $F$ has the mixed $g$-monotone property on $X$ and there exist two elements $x_{0}, y_{0} \in X$ with $g\left(x_{0}\right) \preceq F\left(x_{0}, y_{0}\right)$ and $g\left(y_{0}\right) \succeq F\left(y_{0}, x_{0}\right)$. Suppose that there exists a non-negative real number $L$ such that

$$
d(F(x, y), F(u, v)) \leq L \min \{d(F(x, y), g(u)), d(F(u, v), g(x))\},
$$

for all $(x, y),(u, v) \in X \times X$ with $g(x) \preceq g(u)$ and $g(y) \succeq g(v)$. Further suppose $F(X \times X) \subseteq g(X), g$ is continuous non-decreasing, $g$ and $F$ are compatible, and also suppose either $(a)$ or $(b)$ of Theorem 2.1 holds. Then, there exist $x, y \in X$ such that $F(x, y)=g(x)$ and $F(y, x)=g(y)$, that is, $F$ and $g$ have a coupled coincidence point $(x, y) \in X \times X$.

Now we give sufficient conditions for uniqueness of the coupled coincidence point. If $(X, \preceq)$ is a partially ordered set, then we endow the product space $X \times X$ with the following partial order:

$$
\text { for }(x, y),(u, v) \in X \times X, \quad(u, v) \preceq(x, y) \Leftrightarrow x \succeq u, y \preceq v .
$$

Theorem 2.5. In addition to the hypotheses of Theorem 2.1, suppose that $L=0$ and for every $(x, y),\left(x^{*}, y^{*}\right) \in$ $X \times X$ there exists $(u, v) \in X \times X$ such that $(F(u, v), F(v, u))$ is comparable to $(F(x, y), F(y, x))$ and $\left(F\left(x^{*}, y^{*}\right), F\left(y^{*}, x^{*}\right)\right)$. Then $F$ and $g$ have a unique coupled coincidence point, that is, there exists a unique $(x, y) \in X \times X$ such that $g(x)=F(x, y)$ and $g(y)=F(y, x)$.

Proof. From Theorem 2.1, the set of coupled coincidence points of $F$ and $g$ is non-empty. Suppose that $(x, y)$ and $\left(x^{*}, y^{*}\right)$ are coupled coincidence points of $F$ and $g$, that is, $g(x)=F(x, y), g(y)=F(y, x)$, $g\left(x^{*}\right)=F\left(x^{*}, y^{*}\right)$ and $g\left(y^{*}\right)=F\left(y^{*}, x^{*}\right)$, then we show that

$$
g(x)=g\left(x^{*}\right) \text { and } g(y)=g\left(y^{*}\right) .
$$

By assumption, there exists $(u, v) \in X \times X$ such that $(F(u, v), F(v, u))$ is comparable to $(F(x, y), F(y, x))$ and $\left(F\left(x^{*}, y^{*}\right), F\left(y^{*}, x^{*}\right)\right)$. Put $u_{0}=u, v_{0}=v$, and choose $u_{1}, v_{1} \in X$ so that $g\left(u_{1}\right)=F\left(u_{0}, v_{0}\right)$ and $g\left(v_{1}\right)=F\left(v_{0}, u_{0}\right)$. Then, proceeding as in the proof of Theorem 2.1, we can inductively define sequences $\left\{g\left(u_{n}\right)\right\},\left\{g\left(v_{n}\right)\right\}$ such that

$$
g\left(u_{n+1}\right)=F\left(u_{n}, v_{n}\right) \text { and } g\left(v_{n+1}\right)=F\left(v_{n}, u_{n}\right) \forall n \geq 0 .
$$

Further, set $x_{0}=x, y_{0}=y, x_{0}^{*}=x^{*}, y_{0}^{*}=y^{*}$ and, on the same way, define the sequences $\left\{g\left(x_{n}\right)\right\},\left\{g\left(y_{n}\right)\right\}$, $\left\{g\left(x_{n}^{*}\right)\right\}$ and $\left\{g\left(y_{n}^{*}\right)\right\}$. Then it is easy to show that

$$
g\left(x_{n}\right) \rightarrow F(x, y), \quad g\left(y_{n}\right) \rightarrow F(y, x), g\left(x_{n}^{*}\right) \rightarrow F\left(x^{*}, y^{*}\right) \text { and } g\left(y_{n}^{*}\right) \rightarrow F\left(y^{*}, x^{*}\right)
$$

as $n \rightarrow+\infty$.

Since $(F(x, y), F(y, x))=\left(g\left(x_{1}\right), g\left(y_{1}\right)\right)=(g(x), g(y))$ and $(F(u, v), F(v, u))=\left(g\left(u_{1}\right), g\left(v_{1}\right)\right)$ are comparable, then $g(x) \preceq g\left(u_{1}\right)$ and $g(y) \succeq g\left(v_{1}\right)$. It is easy to show that $(g(x), g(y))$ and $\left(g\left(u_{n}\right), g\left(v_{n}\right)\right)$ are comparable, that is, $g(x) \preceq g\left(u_{n}\right)$ and $g(y) \succeq g\left(v_{n}\right)$ for all $n \geq 1$. Thus from 2.1), we have

$$
\begin{aligned}
d\left(g(x), g\left(u_{n+1}\right)\right)= & d\left(F(x, y), F\left(u_{n}, v_{n}\right)\right) \\
\leq & \alpha \min \left\{d(F(x, y), g(x)), d\left(F\left(u_{n}, v_{n}\right), g(x)\right)\right\} \\
& +\beta \min \left\{d\left(F(x, y), g\left(u_{n}\right)\right), d\left(F\left(u_{n}, v_{n}\right), g\left(u_{n}\right)\right)\right\} .
\end{aligned}
$$

Now, since $F(x, y)=g(x)$, we get

$$
d\left(g(x), g\left(u_{n+1}\right)\right) \leq \beta \min \left\{d\left(g(x), g\left(u_{n}\right)\right), d\left(F\left(u_{n}, v_{n}\right), g\left(u_{n}\right)\right)\right\}
$$

and hence

$$
d\left(g(x), g\left(u_{n+1}\right)\right) \leq \beta d\left(g(x), g\left(u_{n}\right)\right) .
$$


Again from (2.1), we have

$$
\begin{aligned}
d\left(g\left(v_{n+1}\right), g(y)\right)= & d\left(F\left(v_{n}, u_{n}\right), F(y, x)\right) \\
\leq & \alpha \min \left\{d\left(F\left(v_{n}, u_{n}\right), g\left(v_{n}\right)\right), d\left(F(y, x), g\left(v_{n}\right)\right)\right\} \\
& +\beta \min \left\{d\left(F\left(v_{n}, u_{n}\right), g(y)\right), d(F(y, x), g(y))\right\} .
\end{aligned}
$$

Since $F(y, x)=g(y)$, we get

$$
d\left(g\left(v_{n+1}\right), g(y)\right) \leq \alpha \min \left\{d\left(F\left(v_{n}, u_{n}\right), g\left(v_{n}\right)\right), d\left(g(y), g\left(v_{n}\right)\right)\right\},
$$

and so

$$
d\left(g\left(v_{n+1}\right), g(y)\right) \leq \alpha d\left(g\left(v_{n}\right), g(y)\right) .
$$

From (2.12) and (2.13), we have

$$
\begin{aligned}
d\left(g(x), g\left(u_{n+1}\right)\right)+d\left(g(y), g\left(v_{n+1}\right)\right) \leq & \beta d\left(g(x), g\left(u_{n}\right)\right)+\alpha d\left(g\left(v_{n}\right), g(y)\right) \\
\leq & (\alpha+\beta)\left[d\left(g(x), g\left(u_{n}\right)\right)+d\left(g(y), g\left(v_{n}\right)\right)\right] \\
\leq & (\alpha+\beta)^{2}\left[d\left(g(x), g\left(u_{n-1}\right)\right)+d\left(g(y), g\left(v_{n-1}\right)\right)\right] \\
& \cdots \\
\leq & (\alpha+\beta)^{n+1}\left[d\left(g(x), g\left(u_{0}\right)\right)+d\left(g(y), g\left(v_{0}\right)\right)\right] .
\end{aligned}
$$

Taking the limit as $n \rightarrow+\infty$, we get $\lim _{n \rightarrow+\infty}\left[d\left(g(x), g\left(u_{n}\right)\right)+d\left(g(y), g\left(v_{n}\right)\right)\right]=0$. It implies that

$$
\lim _{n \rightarrow+\infty} d\left(g(x), g\left(u_{n}\right)\right)=\lim _{n \rightarrow+\infty} d\left(g(y), g\left(v_{n}\right)\right)=0 .
$$

Following the same lines as above, one can show that

$$
\lim _{n \rightarrow+\infty} d\left(g\left(x^{*}\right), g\left(u_{n}\right)\right)=\lim _{n \rightarrow+\infty} d\left(g\left(y^{*}\right), g\left(v_{n}\right)\right)=0 .
$$

By the triangle inequality, 2.14 and 2.15), we get

$$
\begin{aligned}
& d\left(g(x), g\left(x^{*}\right) \leq d\left(g(x), g\left(u_{n+1}\right)\right)+d\left(g\left(x^{*}\right), g\left(u_{n+1}\right)\right) \rightarrow 0 \text { as } n \rightarrow+\infty,\right. \\
& d\left(g(y), g\left(y^{*}\right) \leq d\left(g(y), g\left(v_{n+1}\right)\right)+d\left(g\left(y^{*}\right), g\left(v_{n+1}\right)\right) \rightarrow 0 \text { as } n \rightarrow+\infty .\right.
\end{aligned}
$$

Therefore, we have $g(x)=g\left(x^{*}\right)$ and $g(y)=g\left(y^{*}\right)$ and so 2.11 holds.

If $g=I$, the identity mapping in Theorem 2.5, then we deduce the following corollary.

Corollary 2.6. In addition to the hypotheses of Corollary 2.2, suppose that $L=0$ and for every $(x, y),\left(x^{*}, y^{*}\right) \in$ $X \times X$ there exists $a(u, v) \in X \times X$ such that $(F(u, v), F(v, u))$ is comparable to $(F(x, y), F(y, x))$ and $\left(F\left(x^{*}, y^{*}\right), F\left(y^{*}, x^{*}\right)\right)$. Then $F$ has a unique coupled fixed point, that is, there exists a unique $(x, y) \in X \times X$ such that $x=F(x, y)$ and $y=F(y, x)$.

Now, we state and prove the last theorem of this paper.

Theorem 2.7. In addition to the hypotheses of Theorem 2.1, if $g\left(x_{0}\right)$ and $g\left(y_{0}\right)$ are comparable and $L=0$, then $F$ and $g$ have a coupled coincidence point $(x, y)$ such that $g(x)=F(x, y)=F(y, x)=g(y)$.

Proof. By Theorem 2.1. we can construct two sequences $\left\{x_{n}\right\}$ and $\left\{y_{n}\right\}$ in $X$ such that $g\left(x_{n}\right) \rightarrow g(x)$ and $g\left(y_{n}\right) \rightarrow g(y)$, where $(x, y)$ is a coincidence point of $F$ and $g$. Suppose $g\left(x_{0}\right) \preceq g\left(y_{0}\right)$, then it is an easy matter to show that

$$
g\left(x_{n}\right) \preceq g\left(y_{n}\right) \forall n \geq 0 .
$$


Thus, by (2.1) we have

$$
\begin{aligned}
d\left(g\left(x_{n}\right), g\left(y_{n}\right)\right)= & d\left(F\left(x_{n-1}, y_{n-1}\right), F\left(y_{n-1}, x_{n-1}\right)\right) \\
\leq & \alpha \min \left\{d\left(F\left(x_{n-1}, y_{n-1}\right), g\left(x_{n-1}\right)\right), d\left(F\left(y_{n-1}, x_{n-1}\right), g\left(x_{n-1}\right)\right)\right\} \\
& +\beta \min \left\{d\left(F\left(x_{n-1}, y_{n-1}\right), g\left(y_{n-1}\right)\right), d\left(F\left(y_{n-1}, x_{n-1}\right), g\left(y_{n-1}\right)\right)\right\} \\
= & \alpha \min \left\{d\left(g\left(x_{n}\right), g\left(x_{n-1}\right)\right), d\left(g\left(y_{n}\right), g\left(x_{n-1}\right)\right)\right\} \\
& +\beta \min \left\{d\left(g\left(x_{n}\right), g\left(y_{n-1}\right)\right), d\left(g\left(y_{n}\right), g\left(y_{n-1}\right)\right)\right\} .
\end{aligned}
$$

By taking the limit as $n \rightarrow+\infty$, we get $d(g(x), g(y))=0$. Hence $F(x, y)=g(x)=g(y)=F(y, x)$. Similar arguments can be used if $g\left(y_{0}\right) \preceq g\left(x_{0}\right)$. To avoid repetitions details are omitted. This makes end to the proof.

If we assume $g=I$ in Theorem 2.7, then we deduce the following corollary.

Corollary 2.8. In addition to the hypotheses of Corollary 2.1, if $x_{0}$ and $y_{0}$ are comparable and $L=0$, then $F$ has a coupled fixed point, that is, there exists $x$ such that $F(x, x)=x$.

Example 2.9. Let $X=[0,+\infty)$. Then $(X, \preceq)$ is a partially ordered set with the natural ordering of real numbers. Let $d(x, y)=|x-y|$ for $x, y \in X$. Define $g: X \rightarrow X$ by $g(x)=\frac{4 x^{2}}{\min \{\alpha, \beta\}}$ with $0<\alpha+\beta<1$, and $F: X \times X \rightarrow X$ by

$$
F(x, y)=\left\{\begin{array}{lll}
\frac{x^{2}-y^{2}}{4} & \text { if } & x>y \\
0 & \text { if } & x \leq y
\end{array}\right.
$$

Denote $\delta=\min \{\alpha, \beta\}$. By routine calculations, the reader can easily verify that the following assumptions hold:

(I) $(X, d)$ is a complete metric space;

(II) $F$ has the mixed $g$-monotone property;

(III) $\left(x_{0}, y_{0}\right)=(0, \sqrt{\delta}) \Rightarrow g\left(x_{0}\right)=0=F\left(x_{0}, y_{0}\right)$ and $g\left(y_{0}\right)=4>\frac{\delta}{4}=F\left(y_{0}, x_{0}\right) \quad\left(\right.$ as $\left.x_{0}<y_{0}\right)$;

(IV) $F(X \times X) \subseteq g(X)$;

(V) $F$ and $g$ are continuous; $g$ is non-decreasing.

Here, we show only that $F$ and $g$ are compatible and condition 2.1) in Theorem 2.1 is satisfied for all real numbers $\alpha, \beta$, with $0<\alpha+\beta<1$, and $L \geq 0$.

- $F$ and $g$ are compatible.

Consider two sequences $\left\{x_{n}\right\}$ and $\left\{y_{n}\right\}$ in $X$ such that

$$
\lim _{n \rightarrow+\infty} F\left(x_{n}, y_{n}\right)=\lim _{n \rightarrow+\infty} g\left(x_{n}\right)=x \in X
$$

and

$$
\lim _{n \rightarrow+\infty} F\left(y_{n}, x_{n}\right)=\lim _{n \rightarrow+\infty} g\left(y_{n}\right)=y \in X
$$

We have to prove that

$$
\left\{\begin{array}{l}
\lim _{n \rightarrow+\infty} d\left(g\left(F\left(x_{n}, y_{n}\right)\right), F\left(g\left(x_{n}\right), g\left(y_{n}\right)\right)\right)=0 \\
\lim _{n \rightarrow+\infty} d\left(g\left(F\left(y_{n}, x_{n}\right)\right), F\left(g\left(y_{n}\right), g\left(x_{n}\right)\right)\right)=0 .
\end{array}\right.
$$

We claim that $(x, y)=(0,0)$. In fact, suppose that $x>0$. From $(2.16)$ and the definition of $F$, there exists $n_{0} \in \mathbb{N}$ such that $x_{n}>y_{n}$ for all $n \geq n_{0}$. Then, from (2.17) and the definition of $F$, we get

$$
0=\lim _{n \rightarrow+\infty} F\left(y_{n}, x_{n}\right)=\lim _{n \rightarrow+\infty} g\left(y_{n}\right)=y
$$

From the definition of $g$, this implies that

$$
\lim _{n \rightarrow+\infty} g\left(y_{n}\right)=\lim _{n \rightarrow+\infty} \frac{4 y_{n}^{2}}{\delta}=y=0
$$


that is,

$$
\lim _{n \rightarrow+\infty} y_{n}=y=0 .
$$

Now, using (2.16) and the definition of $F$, we obtain

$$
\lim _{n \rightarrow+\infty} F\left(x_{n}, y_{n}\right)=\lim _{n \rightarrow+\infty} \frac{x_{n}^{2}-y_{n}^{2}}{4}=\lim _{n \rightarrow+\infty} \frac{x_{n}^{2}}{4}=x .
$$

Using (2.16) and the definition of $g$, we have

$$
\lim _{n \rightarrow+\infty} \frac{4 x_{n}^{2}}{\delta}=x
$$

From the uniqueness of the limit, we get

$$
4 x=\frac{\delta x}{4},
$$

that is,

$$
(16-\delta) x=0 .
$$

Since $0<\delta<1$, we obtain that $x=0$, which is a contradiction. Then, $x=0$. Similarly, one can also show that $y=0$. Then, we have

$$
\lim _{n \rightarrow+\infty} F\left(x_{n}, y_{n}\right)=\lim _{n \rightarrow+\infty} g\left(x_{n}\right)=\lim _{n \rightarrow+\infty} F\left(y_{n}, x_{n}\right)=\lim _{n \rightarrow+\infty} g\left(y_{n}\right)=0 .
$$

Now, (2.18) follows immediately from (2.19), the continuity of $F$, the continuity of $g$ and the continuity of $d$. Thus we proved that $F$ and $g$ are compatible.

- Condition (2.1) holds, for all $(x, y),(u, v) \in X \times X$ with $g(x) \preceq g(u)$ and $g(y) \succeq g(v)$.

We distinguish the following four cases:

Case 1. If $x \leq y$ and $u \leq v$, then we have

$$
\begin{aligned}
d(F(x, y), F(u, v))= & d(0,0)=0 \leq \alpha d\left(0, \frac{4 x^{2}}{\delta}\right)+\beta d\left(0, \frac{4 u^{2}}{\delta}\right) \\
& +L \min \left\{d\left(0, \frac{4 u^{2}}{\delta}\right), d\left(0, \frac{4 x^{2}}{\delta}\right)\right\} .
\end{aligned}
$$

Case 2. if $x \leq y$ and $u>v$, then we have

$$
\begin{aligned}
d(F(x, y), F(u, v))= & d\left(0, \frac{u^{2}-v^{2}}{4}\right)=\frac{u^{2}-v^{2}}{4} \leq \frac{u^{2}}{4}<\beta \frac{15 u^{2}}{4 \delta} \\
< & \alpha \min \left\{d\left(0, \frac{4 x^{2}}{\delta}\right), d\left(\frac{u^{2}-v^{2}}{4}, \frac{4 x^{2}}{\delta}\right)\right\} \\
& +\beta \min \left\{d\left(0, \frac{4 u^{2}}{\delta}\right), d\left(\frac{u^{2}-v^{2}}{4}, \frac{4 u^{2}}{\delta}\right)\right\} \\
& +L \min \left\{d\left(0, \frac{4 u^{2}}{\delta}\right), d\left(\frac{u^{2}-v^{2}}{4}, \frac{4 x^{2}}{\delta}\right)\right\} .
\end{aligned}
$$

Case 3. If $x>y$ and $u>v$, without restriction of generality we suppose $x<u$, and then we have

$$
\begin{aligned}
d(F(x, y), F(u, v))= & d\left(\frac{x^{2}-y^{2}}{4}, \frac{u^{2}-v^{2}}{4}\right)=\frac{1}{4}\left|u^{2}-v^{2}-x^{2}+y^{2}\right| \leq \frac{1}{2} u^{2} \\
< & \beta \frac{15 u^{2}}{4 \delta}<\alpha \min \left\{d\left(\frac{x^{2}-y^{2}}{4}, \frac{4 x^{2}}{\delta}\right), d\left(\frac{u^{2}-v^{2}}{4}, \frac{4 x^{2}}{\delta}\right)\right\} \\
& +\beta \min \left\{d\left(\frac{x^{2}-y^{2}}{4}, \frac{4 u^{2}}{\delta}\right), d\left(\frac{u^{2}-v^{2}}{4}, \frac{4 u^{2}}{\delta}\right)\right\} \\
& +L \min \left\{d\left(\frac{x^{2}-y^{2}}{4}, \frac{4 u^{2}}{\delta}\right), d\left(\frac{u^{2}-v^{2}}{4}, \frac{4 x^{2}}{\delta}\right)\right\} .
\end{aligned}
$$


Case 4. If $x>y$ and $u \leq v$, then, from $g(x) \preceq g(u)$ and $g(y) \succeq g(v)$, it follows $v \geq u \geq x>y \geq v$. This is a contradiction, and so this case must not be considered.

Thus condition 2.1 holds in all the cases. Hence by Theorem 2.1, $F$ and $g$ have a coupled coincidence point $(0,0) \in X \times X$. (Moreover, $(0,0)$ is a coupled fixed point of $F$ ).

On the other hand, we have

$$
d(F(2,1), F(3,1 / 2))=\frac{23}{16} \text { and } \quad \frac{d(2,3)+d(1,1 / 2)}{2}=\frac{3}{4} .
$$

Then, there is no $k \in[0,1)$ such that

$$
d(F(x, y), F(u, v)) \leq \frac{k}{2}[d(x, u)+d(y, v)] \text { for all } x \leq u, y \geq v .
$$

Then, Theorem 2.1 of Bhaskar and Lakshmikantham [4] cannot be applied in this case. Moreover, there is no function $\phi:[0,+\infty) \rightarrow[0,+\infty)$, with $\phi(t)<t$ and $\lim _{r \rightarrow t^{+}} \phi(r)<t$ for each $t>0$, such that

$$
d(F(x, y), F(u, v)) \leq \phi\left(\frac{d(x, u)+d(y, v)}{2}\right) \text { for all } x \leq u, y \geq v .
$$

Then, also Theorem 2.1 of Lakshmikantham and Ćirić [11] cannot be applied in this case.

\section{Acknowledgements:}

The authors are thankful to the referee for his/her valuable comments and suggestions. The third author is supported by Università degli Studi di Palermo, Local University Project R. S. ex 60\%.

\section{References}

[1] R.P. Agarwal, M.A. El-Gebeily and D. O'Regan, Generalized contractions in partially ordered metric spaces, Appl. Anal. 87 (2008), 1-8. 1

[2] I. Altun and H. Simsek, Some fixed point theorems on ordered metric spaces and application, Fixed Point Theory Appl. 2010 (2010), Article ID 621492, 20 pages. 1

[3] A. Amini-Harandi and H. Emami, A fixed point theorem for contraction type maps in partially ordered metric spaces and application to ordinary differential equations, Nonlinear Anal. 72 (2010), 2238-2242. 1 .

[4] T.G. Bhaskar and V. Lakshmikantham, Fixed point theorems in partially ordered metric spaces and applications, Nonlinear Anal. 65 (2006), 1379-1393. 1, 1, 2.9

[5] B. Choudhury and A. Kundu, A coupled coincidence point result in partially ordered metric spaces for compatible mappings, Nonlinear Anal. 73 (2010), 2524-2531. 1

[6] Lj.B. Ćirić, N. Cakić, M. Rajović and J.S. Ume, Monotone generalized nonlinear contractions in partially ordered metric spaces, Fixed point Theory Appl. 2008 (2008), Article ID 131294, 11 pages. 1

[7] Z. Drici, F.A. McRae and J. Vasundhara Devi, Fixed-point theorems in partially ordered metric spaces for operators with PPF dependence, Nonlinear Anal. 67 (2007), 641-647. 1

[8] J. Harjani and K. Sadarangani, Fixed point theorems for weakly contractive mappings in partially ordered sets, Nonlinear Anal. 71 (2008), 3403-3410. 1

[9] J. Harjani and K. Sadarangani, Generalized contractions in partially ordered metric spaces and applications to ordinary differential equations, Nonlinear Anal. 72 (2010), 1188-1197. 1

[10] N. Hussain, M.H. Shah and M.A. Kutbi, Coupled coincidence point theorems for nonlinear contractions in partially ordered quasi-metric spaces with a Q-function, Fixed point Theory Appl. 2011 (2011), Article ID 703938, 21 pages. 1

[11] V. Lakshmikantham and Lj.B. Ćirić, Coupled fixed point theorems for nonlinear contractions in partially ordered metric spaces, Nonlinear Anal. 70 (2009), 4341-4349. 1, 1, 1.2, 2.9

[12] H.K. Nashine and I. Altun, Fixed point theorems for generalized weakly contractive condition in ordered metric spaces, Fixed point Theory Appl. 2011 (2011), Article ID 132367, 20 pages. 1

[13] H.K. Nashine and B. Samet, Fixed point results for mappings satisfying $(\psi, \varphi)$-weakly contractive condition in partially ordered metric spaces, Nonlinear Anal. 74 (2011), 2201-2209. 1

[14] H.K. Nashine, B. Samet, C. Vetro, Monotone generalized nonlinear contractions and fixed point theorems in ordered metric spaces, Math. Comput. Modelling 54 (2011), 712-720. 1 
[15] J.J. Nieto and R.R. Lopez, Contractive mapping theorems in partially ordered sets and applications to ordinary differential equations, Order 22 (2005), 223-239. 1

[16] J.J. Nieto and R.R. Lopez, Existence and uniqueness of fixed point in partially ordered sets and applications to ordinary differential equations, Acta Math. Sinica, Engl. Ser. 23 (2007), 2205-2212. 1

[17] A.C.M. Ran and M.C.B. Reurings, A fixed point theorem in partially ordered sets and some applications to matrix equations, Proc. Amer. Math. Soc. 132 (2004), 1435-1443. 1

[18] D. O'Regan and A. Petrutel, Fixed point theorems for generalized contractions in ordered metric spaces, J. Math. Anal. Appl. 341 (2008), 1241-1252. 1

[19] B. Samet, Coupled fixed point theorems for a generalized Meir-Keeler contraction in partially ordered metric spaces, Nonlinear Anal. 72 (2010), 4508-4517. 1

[20] W. Shatanawi, Partially ordered cone metric spaces and coupled fixed point results, Comput. Math. Appl. 60 (2010), 2508-2515. 1

[21] Y. Wu, New fixed point theorems and applications of mixed monotone operator, J. Math. Anal. Appl. 341 (2008), 883-893. 1

[22] Y. Wu and Z. Liang, Existence and uniqueness of fixed points for mixed monotone operators with applications, Nonlinear Anal. 65 (2006), 1913-1924. 